\title{
Research on Several Tool Chuck Technology in High Speed Milling
}

\author{
Zhao Zhenyu $^{1, a^{*}}$, Xu Xiaomei $^{1, \mathrm{~b}}$, Zhou Yongquan ${ }^{1, \mathrm{c}}$, Xiao Haibin $^{1, \mathrm{~d}}$ \\ ${ }^{1}$ Shenzhen Institute of Information Technology, Shenzhen, China
}

\begin{abstract}
In order to meet the requirements of high-speed precision machining technology, the paper elaborates the tool clamping technology commonly used in high-precision machining, such as the static pressure expansion chuck, CoroGrip chuck, and stress locking chuck and so on. How to correctly select the tool clamping system, the characteristics of the tool clamping system and the existing problems are analyzed.
\end{abstract}

\section{Introduction}

In recent years, due to the continuous development of CNC cutting machine tools and tool manufacturing made great achievements in the field, it makes the level of metal cutting to high-power, high-speed, high-precision continuously improved. It also sets higher and higher requirements on the important part of the tool clamping system that connects the tool and the machine tool. The application of high-speed cutting technology and precision machining technology requirements need highperformance CNC machine tool system tool chuck higher and higher requirements. As long as the tool system to improve the clamping accuracy, we must try to make the tool to be precise and reliable positioning, to ensure adequate clamping force, strict control and improve tooling system with precision, and increase the clamping length, and optimize the structural design and reasonable selection[1].

The paper focuses on several kinds of tool clips suitable for high-speed machining, such as static pressure expansion tool holder, CoroGrip chuck, and stress locking chuck and so on.

\section{Technical analysis}

\subsection{Static pressure expansion chuck}

The static pressure expansion chuck is a high precision tool holder with static pressure expansion principle. The structure is shown in Fig.1. It has excellent technical performance, which is suitable for holding drills, reamer, milling cutter in machining center, high precision boring milling machine and flexible production line. Currently in Germany, static pressure expansion chuck has been widely used in manufacturing industries such as automobiles and machinery. In China, many machining enterprises have successfully used the tool holder.

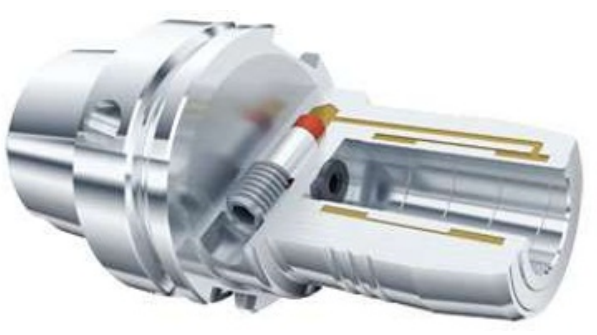

Fig.1 static pressure expansion chuck

The structural principle of static expansion chuck is shown in Fig.2.The holder main body and the expansion of the clamping hole wall have a circular closed oil cavity; the oil cavity fills with dedicated hydraulic oil. The oil pressure can be evenly delivered to every part of the oil sealed cavity, at the same time also to increase structural damping, to improve the dynamic characteristics of chuck, and to reduce the vibration and improve the quality of machining. The expansion wall of the clamping hole is set by precise calculation. It has a good elasticity and can produce the desired amount of expansion when the oil pressure reaches the set value. The clamping hole wall has ring slot, and can accommodate the cutting tool residual lubricant, and keep the clamping hole wall clean and ensure reliable transmission of torque [2-3].

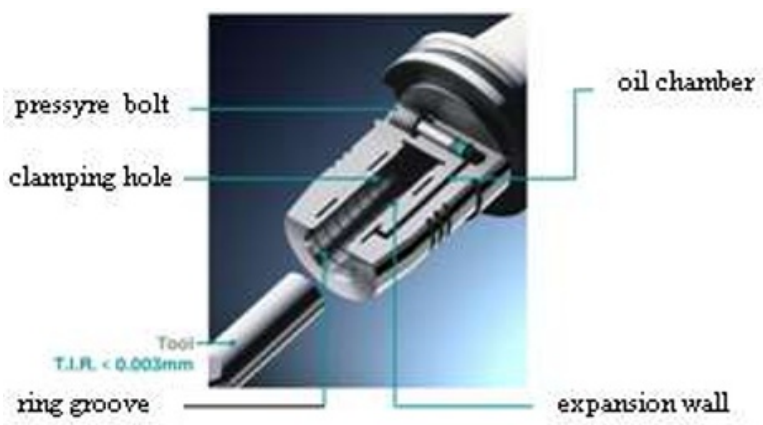

Fig.2 Static pressure expansion chuck working principle

\footnotetext{
$\bar{a}$ Corresponding author: yxpzzy01 @ 163.com
} 
The static pressure expansion tool holder produced by the German company has the following excellent properties. The clamping rotary precision is less than $3 \mathrm{um}$. Repeated clamping precision is less than $2 \mathrm{um}$. It has stable and reliable clamping force. It can deliver high torque. It has excellent damping performance. The clamping system has the whole sealing structure, no abrasion and durability. When the outer diameter of the cutter is $6-8 \mathrm{~mm}$, the precision level of the cutter bar is h6. When the outer diameter of the tool is greater than $8 \mathrm{~mm}$, the precision level of the pole can be relaxed to $\mathrm{h} 7$.

\subsection{CoroGrip chuck}

Sandvik has developed the CoroGrip chuck, as shown in Fig.3. The product uses a hydraulic device to push the cone, which is measured in $3 \mathrm{D}$ with a radial beat of 26um. The chuck is more reliable. Its rigidity is higher than the hydraulic clamping head, and the clamping time is shorter than the heat shrinkable head [4].

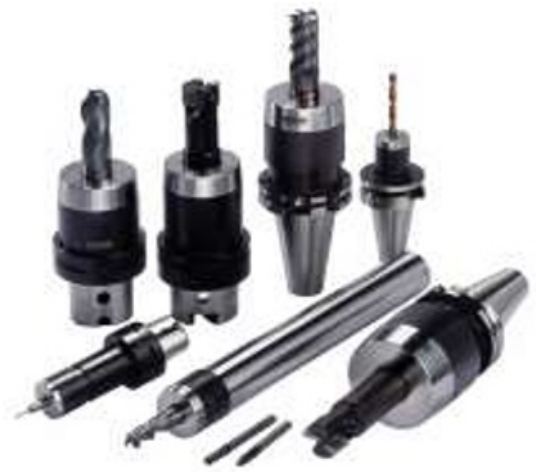

Fig.3 CoroGrip chuck

CoroGrip chuck is acted on the wedge type machine tool clamping jaw of the hydraulic pressure to realize the clamping function at the same level products. CoroGrip chuck clamping force is unusually high and has a very high precision, suitable for drilling and from superfinishing to reload all rough machining milling process. CoroGrip chuck has all the pins on its own balance. During the long process of processing, the pulsation amount is always consistent, thus effectively improving the service life of the cutter and ensuring the quality of the parts.

The high clamping force required for CoroGrip chuck is provided by the external hydraulic pump. The clamp has two different hydraulic pumps. They are the manual pump and the pneumatic motor drive pump. The pneumatic pump uses the general pneumatic system in the workshop. With these pumps, it is easy to change the knife. It can be changed for less than 20 seconds, and the same clamping force is always on the handle.

The HydroGrip chuck is used to achieve the tool clamping by the pressure of the membrane on the handle of the handle. The clamping principle is shown in Fig.4. The clamping force is more than three times that of the traditional chuck.

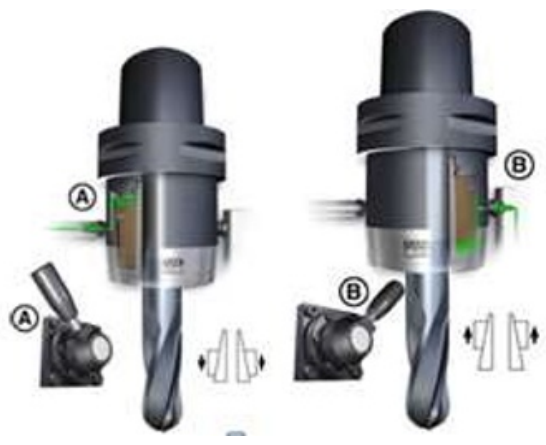

Fig.4 CoroGrip chuck working principle

CoroGrip high-precision power chuck has the following several advantages. It can improve the surface quality. At three times in diameter, its beating quantity is $6 \mathrm{um}$ or less. It can prolong tool life. According to the rule of thumb, According to rule of thumb, every $10 \mu \mathrm{m}$ increase in runout results in a 50\% reduction in tool life. It is almost no vibration and low noise level. The repeatability is high and the clamping force remains unchanged after using 15,000 cycles. Heavy-duty heavy processing has excellent performance, and unusually high clamping force and rigid structure prevent tool slipping.

\subsection{Stress-locking chuck}

There are two main types of stress locking chuck. They are TRIBOS-R and TRIBOS-S, as shown in Fig.5. The shape of the TRIBOS-R chuck is robust and has a specially designed vibration reducing cavity structure which can be used for rough cutting and heavy cutting. The TRIBOS-S chuck has a very fine external diameter, which can be used to solve the problem of interference in a very restricted area of processing space.

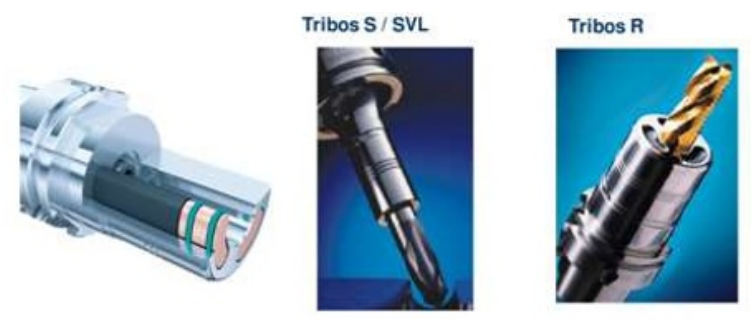

Fig.5 TRIBOS chuck

Schunk Company has two basic TRIBOS chuck. One chuck is tool extension rod, and it can have the effect of prolonging tool, but it must be associated with a cutting tool holder which is used. Another chuck is for a complete tool holder, and it can be directly as well as clamping tool with the machine tool spindle.

The clamping slewing accuracy and repeat clamping accuracy is less than $3 \mathrm{um}$ in Stress-locking clamping system. Compared with chuck TRIBOS-S, TRIBOS-R chuck increases the clamping piece of overall diameter, and designs the special cavity structure of vibration reduction. The cavity is filled with thermosetting plastics, make the cutter holder rigidity and clamping force have been greatly improved, can be used for heavy cutting processing. The two kinds of chuck can reduce the 
vibration of the tool and improve the service life of the cutter.

The holding principle of TRIBOS-R stress locking chuck is shown in Figure.6. The clamp hole has a special geometrical shape with axial-symmetric shape, as shown in Figure.6a. In the original state, the tool cannot be inserted into the holing hole. When installing a tool, a special loader is used to pressurize the holding section from outside, forcing the clamping hole to become a round hole in the range of elastic deformation, as shown in Figure.6b. Insert the cutter into the clamp hole smoothly, as shown in Figure.6c.Then, loosen the loader and remove the external load, and the cutter is firmly clamped with deformation recovery force, as shown in Figure.6d. Also, the tool can be easily removed or replaced with a loader. Because the clamping motion of TRIBOS has the characteristics of axial-symmetric, it has extremely high clamping accuracy. This tool holder is also very suitable for high speed machining [5].

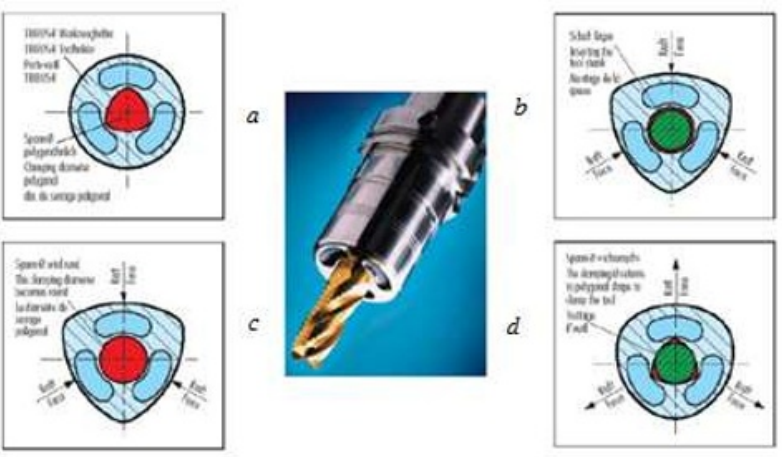

Figure.6 TRIBOS-R chuck working principle

The TRIBOS-R chuck and the TRIBOS-S chuck, the two handles have the same principle. The holding principle of TRIBOS-S is shown in Fig.7 [6]. The inside of TRIBOS-S chuck is very small. It can be used to make a tool extension rod for the occasion of needing lengthening knives, such as the processing of deep cavity mould. It can also be directly used as a tool holder for the machining of parts with geometric interference. Because of its thin outer diameter and relatively poor rigidity, it can only be used for light cutting [6].
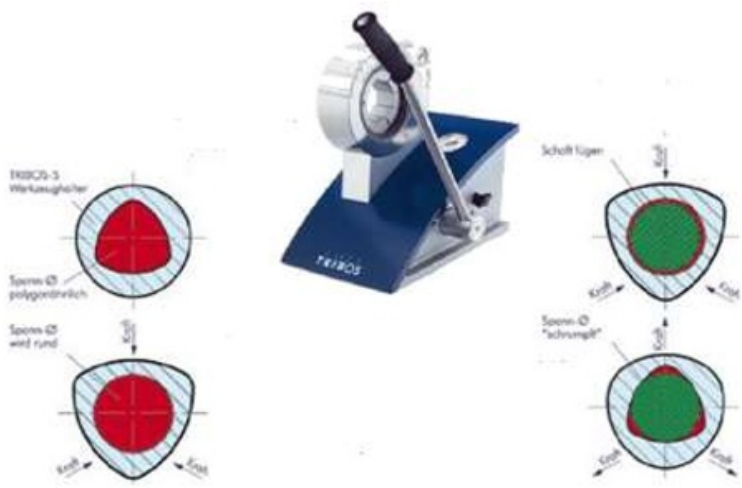

Fig.7 TRIBOS-S chuck working principle

TRIBOS-SVL is a tool extension bar, as shown in Fig.8. Its working principle and performance characteristics are the same as the TRIBOS-S chuck. Its clamping accuracy and repeat clamping precision are less than 3um.The standard series of TRIBOS-SVL cutters have a length of $100 \mathrm{~mm}$ and $150 \mathrm{~mm}$, with a cylindrical handle of $\Phi 12 \mathrm{~mm}, \Phi 20 \mathrm{~mm}$ and $\Phi 32 \mathrm{~mm}$.

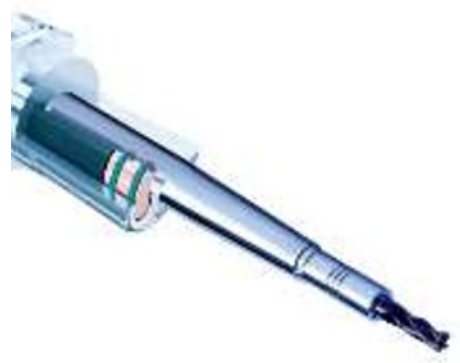

Fig.8 TRBIOS-SVL extension chucks

Static pressure expansion chuck and the stress locking chuck, their performance is shown in Table.1.

Table.1 The performance contrast of the chuck

\begin{tabular}{|c|l|l|l|}
\hline Chuck type & $\begin{array}{l}\text { Static pressure } \\
\text { expansion } \\
\text { chuck }\end{array}$ & \multicolumn{2}{|c|}{ stress locking chuck } \\
\cline { 3 - 4 } & $\begin{array}{l}\text { DRIBOS -S } \\
\text { loading and } \\
\text { unloading } \\
\text { tools without } \\
\text { special } \\
\text { equipment }\end{array}$ & $\begin{array}{l}\text { Super fine } \\
\text { appearance }\end{array}$ & $\begin{array}{l}\text { Damping, } \\
\text { high radial } \\
\text { stiffness }\end{array}$ \\
\hline $\begin{array}{c}\text { Clamping } \\
\text { range }\end{array}$ & $3-32 \mathrm{~mm}$ & $0.3-32 \mathrm{~mm}$ & $3-32 \mathrm{~mm}$ \\
\hline $\begin{array}{c}\text { Radial } \\
\text { runout }\end{array}$ & $<0.003 \mathrm{~mm}$ & $<0.003 \mathrm{~mm}$ & $<0.003 \mathrm{~mm}$ \\
\hline $\begin{array}{c}\text { Work } \\
\text { speed }\end{array}$ & $<50000 \mathrm{~min}^{-1}$ & $\begin{array}{l}<85000 \mathrm{~min} \text { - } \\
1\end{array}$ & $\begin{array}{l}<55000 \mathrm{~min}^{-} \\
1\end{array}$ \\
\hline $\begin{array}{c}\text { Change the } \\
\text { diameter }\end{array}$ & $\begin{array}{l}\text { Use a smaller } \\
\text { diameter } \\
\text { sleeve }\end{array}$ & $\begin{array}{l}\text { Use a } \\
\text { smaller } \\
\text { diameter } \\
\text { sleeve }\end{array}$ & $\begin{array}{l}\text { Use a } \\
\text { smaller } \\
\text { diameter } \\
\text { sleeve }\end{array}$ \\
\hline $\begin{array}{c}\text { Loading } \\
\text { and } \\
\text { unloading } \\
\text { tools }\end{array}$ & Allen wrench & loader & loader \\
\hline
\end{tabular}

\section{Summary}

The paper introduces several common tool clamping system, the static pressure expansion type chuck, CoroGrip chuck, stress locking chuck. These clamping systems reflect the advanced level of cutting tools in international cutting processing. Their successful application in mold manufacturing industry has made important contribution to the modernization of mould manufacturing. 


\section{Acknowledgement}

The authors would like to thank "Science plan project of Shenzhen" (JCYJ20170817112440533, GRCK2017042409562903， JCYJ20160415114050831) and for their financial support.

\section{References}

1. Z.Y. Zhao, C. Y. Wang: Manufacturing technology and machine tools, Vol.12, p.65 (2004)

2. J. Shen, H.Y. Zhang: Tool technology, Vol.39, p.39 (2005)

3. Z.X Yang: Modern manufacturing engineering, Vol.12, p.5 (2002)

4. T. Tan: World manufacturing technology and equipment market, Vol.5, p.100(2009)

5. Q. Y. Zhou, Z.X. Zhou: Machine tool \& hydraulics, Vol.38, p.1 (2010)

6. H. Yuan: Mould industry, Vol.219, p.42(1999) 